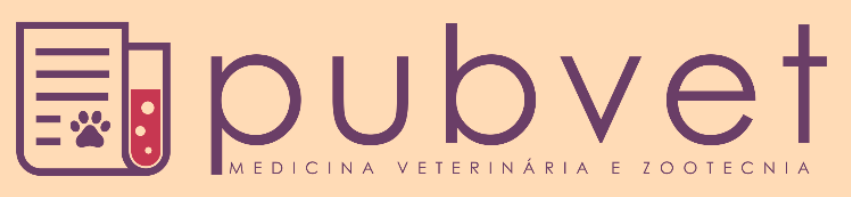

https://doi.org/10.31533/pubvet.v13n11a446.1-6

\title{
Linfangite ulcerativa em equino: relato de caso
}

\author{
Nayara Martins Leite ${ }^{1} \bullet$, Mylano Viana da Rocha ${ }^{2} \bullet$, Karoline Milhomem de Souza ${ }^{3} \bullet$, Paula \\ Bittencourt Vago ${ }^{* *}$
}

${ }^{I}$ Discente da Faculdade Terra Nordeste. Caucaia-CE Brasil.

${ }^{2}$ Discente da Faculdade Terra Nordeste. Caucaia-CE Brasil.

${ }^{3}$ Médica Veterinária graduada pela Faculdade Terra Nordeste. Fortaleza-CE Brasil.

${ }^{4}$ Docente da Faculdade Terra Nordeste, Departamento de Medicina Veterinária. Fortaleza-CE Brasil.

*Autor para correspondência: E-mail: paula.vago@fatene.edu.br

Resumo. A Linfangite Ulcerativa trata-se de uma patologia infecciosa de caráter bacteriano, que atinge animais sem distinção de raça, idade ou sexo. Tem como principais agentes Corynebacterium pseudotuberculosis, Staphylococcus spp., Streptococcus spp., Pseudomonas aeruginosa e Rhodococcus equi. É uma doença prevalente na Medicina Veterinária apesar de ter profilaxia simples, basicamente higiene e privar os animais do contato com vetores ou outros animais infectados. Seu diagnóstico depende de um exame clínico bem realizado se baseando em sinais clínicos, podendo ser auxiliado por diagnóstico laboratorial identificando o agente causador. $\mathrm{O}$ tratamento se mostra longo e dependente de diagnóstico. O presente estudo tem o objetivo de relatar um caso clínico da doença mostrando a importância de um diagnóstico precoce e diferencial e uso de antibioticoterapia correta. No caso relatado o animal demonstrou sinais clínicos no membro posterior esquerdo como edema, aumento de temperatura, claudicação grau 4 de 5 , foi primeiramente diagnosticado como trauma do membro afetado; e após aparecimento de fistulas, que vieram a drenar secreção purulenta, foi finalmente diagnosticado com Linfangite Ulcerativa. Foi realizado tratamento à base de $\beta$-lactâmicos e medidas terapêuticas como higiene, sendo constatado melhora do quadro clínico do animal em curto espaço de tempo. Tendo em vista que a doença tem prevalência significativa na Medicina Veterinária e pode ser recorrente muitas vezes, além de evitar uso indiscriminado de antibióticos, deve-se ressaltar a importância da higiene referente ao ambiente em que o equino vive como principal método profilático para novos casos e recorrências destes.

Palavras chave: diagnóstico, equinos, infecção, vasos linfáticos

\section{Equine ulcerative lymphangitis: case report}

\begin{abstract}
Ulcerative Lymphangitis is an infectious bacterial disease that affects animals without distinction of race, age or sex. It has as main agents Corynebacterium pseudotuberculosis, Staphylococcus spp., Streptococcus spp., Pseudomonas aeruginosa and Rhodococcus equi. It is a prevalent disease in Veterinary Medicine despite having simple prophylaxis, basically hygiene and depriving the animals of the contact with vectors or other infected animals. Its diagnosis depends on a clinical examination well done based on clinical signs and can be aided by laboratory diagnosis identifying the causative agent. The treatment is long and diagnostic dependent. The present study aims to report a clinical case of the disease showing the importance of an early and differential diagnosis and the use of correct antibiotic therapy. In the case reported the animal showed clinical signs in the left hind limb such as edema, temperature increase, grade 4 claudication of 5 , was first diagnosed as trauma of the affected limb; and after the appearance of fistulas, which came to drain purulent secretion, was finally diagnosed with Ulcerative Lymphangitis. A $\beta$ -
\end{abstract}


lactam treatment and therapeutic measures such as hygiene were performed, and an improvement in the clinical condition of the animal was observed in a short period of time. Considering that the disease has a significant prevalence in Veterinary Medicine and may be recurrent many times, in addition to avoiding indiscriminate use of antibiotics, it should be emphasized the importance of hygiene referring to the environment in which the equine lives as the main prophylactic method for new cases and recurrences of these.

Keywords: diagnosis, horses, infection, lymph vessels

\section{Linfangitis ulcerativa equina: reporte de un caso}

Resumen. La Linfangitis Ulcerativa se trata de una patología infecciosa de carácter bacteriano, que afecta animales sin distinción de raza, edad o sexo. Sus principales agentes son Corynebacterium pseudotuberculosis, Staphylococcus spp., Streptococcus spp., Pseudomonas aeruginosa y Rhodococcus equi. Es una enfermedad frecuente en medicina veterinaria a pesar de tener una profilaxis simple, básicamente higiene y privar los animales del contacto con vectores u otros animales infectados. Su diagnóstico depende de un examen clínico bien realizado basado en signos clínicos pudiendo ser auxiliado por un diagnóstico de laboratorio que identifique el agente causal. El tratamiento es largo y depende del diagnóstico. Este estudio tiene como objetivo relatar un caso clínico de la enfermedad mostrando la importancia del diagnóstico temprano y diferencial y la correcta terapia con antibióticos. En el caso reportado aquí, el animal mostró signos clínicos en la extremidad posterior izquierda, tales como edema, aumento de temperatura, cojera grado 4 de 5, fue diagnosticado por primera vez como trauma de la extremidad afectada; y después la aparición de fístulas, que finalmente drenaron la secreción purulenta, finalmente se le diagnosticó linfangitis ulcerosa. Se realizó tratamiento con $\beta$-lactama y medidas terapéuticas como la higiene, y presentando mejoría del estado clínico del animal en poco tiempo. Dado que la enfermedad tiene una prevalencia significativa en la medicina veterinaria y puede ser recurrente muchas veces, además de evitar el uso indiscriminado de antibióticos, se debe enfatizar la importancia de la higiene con respecto al entorno en el que vive el caballo como el método profiláctico principal para nuevos casos. y recurrencias de estos.

Palabras clave: diagnóstico, equinos, infección, vasos linfáticos

\section{Introdução}

A linfangite ulcerativa é uma infecção bacteriana dos vasos linfáticos subcutâneos e tecidos adjacentes de equinos causada pelas bactérias Corynebacterium pseudotuberculosis, Rhodococcus equi, Staphylococcus spp., Streptococcus spp. e Pseudomonas aeruginosa (Reed et al., 2009; Thomassian, 2006).

As lesões são mais comuns nos membros posteriores, especialmente distais ao jarrete, com formação de nódulos dolorosos, edemaciados, os quais fistulizam, drenando pus com característica cremosa (Reed et al., 2009; Thomassian, 2006). Não existe predileção por idade, sexo ou raça (Guedes et al., 2015).

O tratamento varia de acordo com a manifestação clínica da doença (Guedes et al., 2015). Contudo, de modo geral, exercício, drenagem cirúrgica, higienização e proteção por bandagens da área e longo período de antibióticos fazem parte do protocolo terapêutico (Guedes et al., 2015; Mueller, 2007).

A antibioticoterapia consiste no uso de penicilina, tetraciclina e sulfa com trimetropim, sendo sugeridas em alguns estudos injeções parenterais de penicilina, tetraciclina ou penicilina $G$ procaína, substâncias cujos agentes patogênicos se mostram sensíveis (Guedes et al., 2015; Radostits et al., 2010; Thomassian, 2005; Thomassian, 2006).

A patologia traz um prognóstico reservado para a recuperação completa e se for tratada logo, a terapia pode ser eficaz (Thomassian, 2005; Thomassian, 2006). Bom a reservado em lesões iniciais; reservado a mal se fibrose grave estiver presente (Mueller, 2007). 
Existem métodos eficientes para prevenir a infecção, tais como: higiene dos estábulos, baias, pastos e picadeiros, controle constante de vetores, isolamento dos animais infectados, e evitar a aglomeração constante da população equina (Guedes et al., 2015; Radostits et al., 2010; Sureshjani et al., 2015).

\section{Relato de caso}

O caso descrito no presente trabalho ocorreu no $1^{\circ}$ Regimento de Cavalaria de Guardas - Dragões da Independência, em Brasília - Distrito Federal; no qual a Seção Veterinária Regimental - SVR fica responsável pela assistência médica veterinária aos cavalos lá estabulados.

Chegou a SVR, uma égua Puro Sangue Árabe, de pelagem castanha, cinco anos de idade e pesando aproximadamente $370 \mathrm{~kg}$. O responsável relatou como queixa principal claudicação, informou que, no dia anterior, a égua havia sido trabalhada normalmente, e que não havia apresentado sinais clínicos até chegar a sua baia. Na manhã seguinte foi observado edema evidente e dificuldade de apoiar o membro no chão.

Ao exame clínico, constatou-se claudicação grau 4/5 do membro posterior esquerdo, visualizado inclusive ao passo, dor a palpação e a flexão, aumento de temperatura local e edema no boleto do referido membro. Baseado no histórico e sinais clínicos, o médico veterinário obteve a suspeita de trauma e prescreveu o tratamento de crioterapia por 30 minutos na região de boleto e canela e $10 \mathrm{ml}$ de Phenylartrite ${ }^{\circledR}$ (dexametasona + fenilbutazona), EV, SID, por três dias. Contudo, no terceiro dia de tratamento, o animal apresentou fístulas purulentas na região do boleto, relutância a se locomover e o edema se estendia até o jarrete (Figura 1). Com isso, a suspeita clínica de trauma foi descartada e baseado nas novas apresentações clínicas suspeitou-se de linfangite ulcerativa.

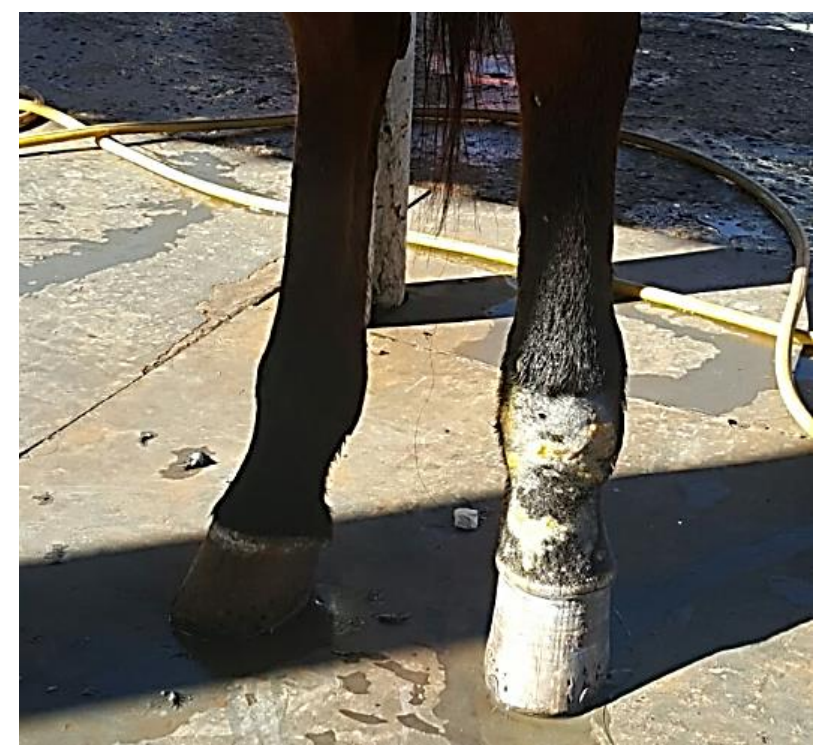

Figura 1. Edema no membro posterior esquerdo desde quartela até o jarrete com fístula na região do boleto.

Baseado na suspeita clínica foi adicionado ao tratamento inicial, antibioticoterapia com Penicilina benzatina, na dose de 20.000 UI/Kg, I.M., SID, por sete dias, e estendido o tempo de aplicação do Phenylartrite ${ }^{\circledR}$ sem período pré-determinado, de acordo com a sintomatologia do animal. Associado ao tratamento sistêmico era realizado higiene das fístulas e imersão do membro em água morna adicionada de iodo por 30 minutos, quatro vezes ao dia. Após a imersão era feito antissepsia com 100ml solução PVPI diluída em soro, a qual, também, era injetada nas fístulas pela sonda acoplada a seringa. O curativo era finalizado com um "mix de pomadas" produzido na SVR contendo Unguento SM ${ }^{\circledR}$ (óxido de zinco + permetrina), Penicilina benzatina e Rifamicina.

No quarto dia da antibioticoterapia, o animal não apresentava melhora na claudicação, edema e as fístulas continuavam drenando secreção purulenta. Ademais, toda a área da coroa do casco estava drenando secreção em grande quantidade e apresentava sinais de descolamento (Figura 2A). Diante disso, foi alterado protocolo terapêutico para Agrodel® (Benzilpenicilina benzatina, benzilpenicilina procaína, benzilpenicilina potássica, sulfato de estreptomicina e piroxicam), na dose de $50.000 \mathrm{UI} / \mathrm{kg}$, 
I.M., SID, por 15 dias; Dimesol ${ }^{\circledR}$ (Dimetilsufóxido) $200 \mathrm{ml}$ diluído em dois litros de soro glicosado a $5 \%$, durante três dias, e metronidazol na dose de $7,5 \mathrm{mg} / \mathrm{kg}$ (40 comprimidos), V.O., SID, durante 15 dias. A administração de Phenylartrite ${ }^{\circledR}$ seguiu com $10 \mathrm{ml}$, EV, SID. A frequência do curativo local aumentou para cinco vezes ao dia, sendo utilizados os mesmos produtos já descritos.

Com uma semana de tratamento, não havia secreção na coroa do casco e o descolamento estava estabilizado. Ainda havia secreção purulenta nas fístulas do boleto, porém em pouca quantidade e a claudicação havia diminuído para grau 3/5, não sendo mais visível ao passo (Figura 2B).

No último da terapia, foi constatada ausência de secreção em todos os pontos fistulados e coroa do casco, edema quase inaparente, sem pulso ou aumento de temperatura no local e sem claudicação (Figura 2C). Foi acrescentada, como medida terapêutica, caminhada puxada pelo cabresto duas vezes ao dia com duração de 30 minutos por vez.

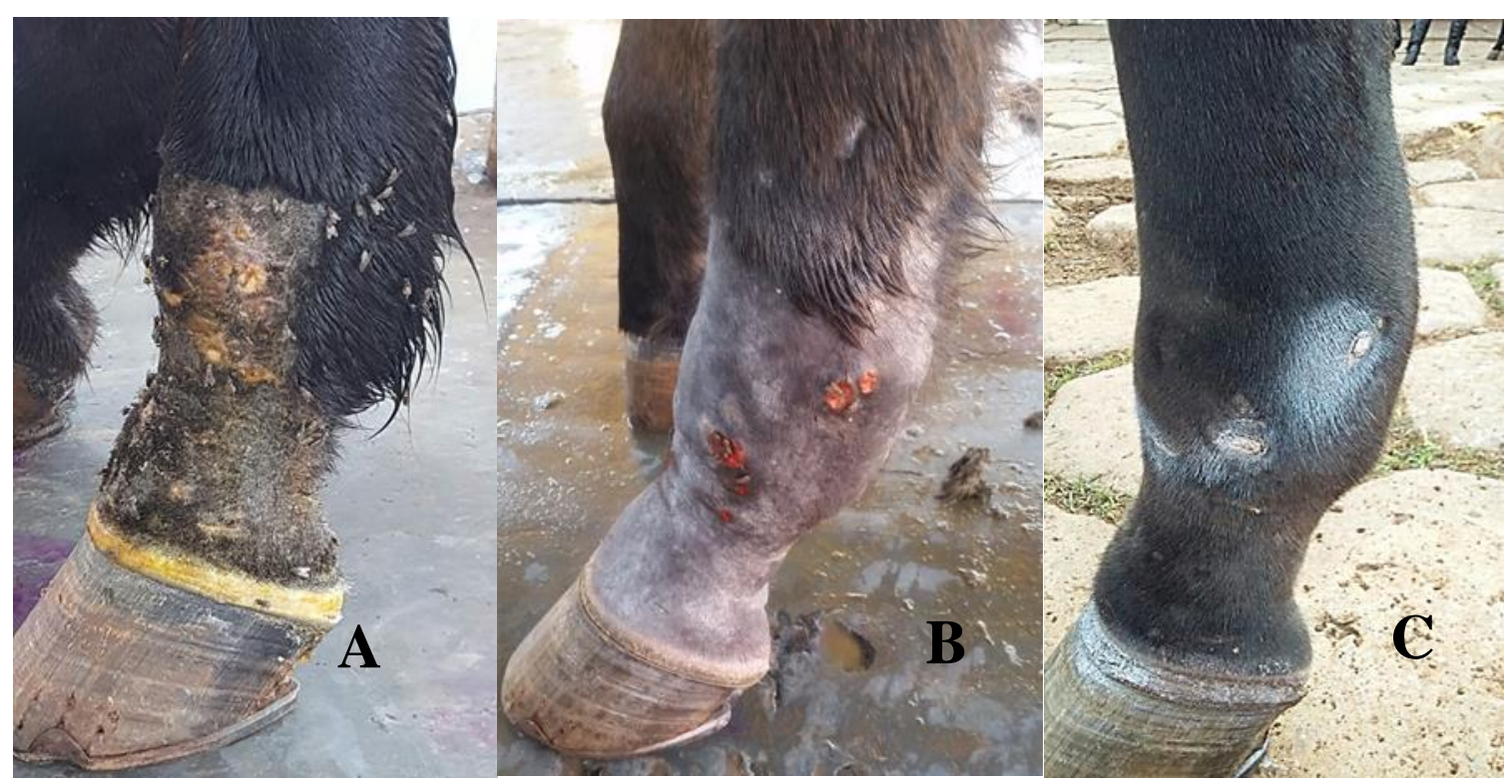

Figura 2. A) Edema, fístulas na região do boleto e coroa do casco com descolamento. B) Evolução do caso com diminuição do edema e da secreção das fístulas, coroa do casco estabilizada e sem secreção. C) Último dia de tratamento.

\section{Discussão}

$\mathrm{O}$ animal apresentava claudicação e edema evidente no boleto do membro posterior esquerdo. Ao exame clínico foi observada claudicação grau $4 / 5$ do referido membro, dor a palpação e a flexão, além de aumento de temperatura no local. Todos os sinais clínicos descritos estão de acordo com literatura no tocante a casos de linfangite ulcerativa (Guedes et al., 2015; Meselu et al., 2018; Radostits et al., 2010; Reed et al., 2009; Smith, 1993; Smith, 2006; Thomassian, 2005; Thomassian, 2006).

O tratamento inicial foi instituído com crioterapia por 30 minutos, pois de acordo com Moreira et al. (2011) agentes físicos, como a crioterapia, quando corretamente indicados e utilizados, podem combater o processo álgico e estudos mostram que se realizada por até 20 minutos diminui a temperatura superficial, do tecido, e reduz a sensação de dor. A analgesia, produzida pela crioterapia, ocorre de forma rápida, porém seu efeito também se dissipa rapidamente. Pode facilitar a recuperação de lesões, visto que a vasoconstrição induzida pelo frio reduz a formação de edemas, bem como a intensidade do dano celular local, por meio da redução do quadro hemorrágico e das demandas metabólicas no tecido lesado (Matheus et al., 2008).

A inflamação pode ocorrer em qualquer tecido vascularizado no organismo. As sequelas da inflamação manifestam-se por cinco sinais cardeais: rubor, calor, tumefação, dor e perda da função em decorrência da vasodilatação e aumento da permeabilidade vascular das vênulas. Segundo Matheus et al. (2008) drogas anti-inflamatórias atuam impedindo a ação das enzimas de degradação do ácido araquidônico, particularmente no grupo das COX, impedindo a liberação excessivas de eicosanoides, o que por si só reduz a sensibilização dos nociceptores. No caso da fenilbutazona, composto da Phenylarthrite ${ }^{\circledR}$, reduz de forma irreversível a enzima COX, mas também tem a capacidade de aumentar 
a reabsosção de íons sódio e cloretos, sendo, portanto, contraindicada em pacientes nefros, hepato ou cardiopatas. A dexametasona, outro composto da Phenylarthrite ${ }^{\circledR}$, é um glicocorticoide que possui efeito anti-inflamatório inibindo muitas moléculas associadas a inflamação, como as citocinas, quimiocinas, metabólitos do ácido araquidônico, moléculas de aderências e inibição da COX2 (Pereira et al., 2007).

No decorrer do tratamento instituído para trauma, houve fistulação de nódulos que apareceram no boleto do membro afetado, o que fez com que o médico veterinário modificasse seu diagnóstico e tratamento. De acordo com Smith (1993), os sinais clínicos apresentados pelo animal com linfangite podem ser confundidos com sinais de outras doenças como traumatismos nos membros, punções por corpos estranhos, ou celulite estafilocócica, e defende a necessidade de diagnóstico diferencial. Diante do aparecimento de fístulas e drenagem de secreção purulenta através destas, justificou-se a instituição de antibioticoterapia, com penicilina benzatina que de acordo com Quinn et al. (2005) e Guedes et al. (2015) é agente inibitório da maioria dos agentes causadores da Linfangite Ulcerativa, como $C$. pseudotuberculosis, Streptococcus e segundo Sureshjani et al. (2015) possui ação moderada sobre o Rhodococcus equi. Autores como Quinn et al. (2005), Melo et al. (2009), Nogradi et al. (2012) e Sureshjani et al. (2015) defendem que a maiorias dos agentes causadores da linfangite ulcerativa são susceptíveis a antimicrobianos $\beta$-lactâmicos em geral. Dessa forma, foi substituído tratamento inicial que era somente com penicilina benzatina por Agrodel plus® um composto produzido com benzilpenicilina benzatina, Benzilpenicilina procaína, Benzilpenicilina potássica, Sulfato de estreptomicina, antibióticos $\beta$-lactâmicos e piroxicam uma substância anti-inflamatória e analgésica. $\mathrm{O}$ metronidazol foi acrescentado ao tratamento justificado por ser comumente usados em tratamentos de infecções causadas por bactérias anaeróbicas de acordo com o que aponta Spinosa et al. (2002) e Grampositivas e Gram-negativas Giguère et al. (2010).

Mesmo com o diagnóstico modificado para linfangite ulcerativa, continuou-se utilizando associação de dexametasona e fenilbutazona (Phenylarthrite ${ }^{\circledR}$ ), visto que Thomassian (2005), Radostits et al. (2010), Guedes et al. (2015) defendem o uso de anti-inflamatório não esteroidal como fenilbutazona ou corticoterapia com dexametasona para aliviar o edema.

Em relação às crostas, foi realizada, sempre antes dos curativos, compressa e pedilúvio quente adicionado de iodo a $10 \%$ para auxiliar a remoção da secreção purulenta de dentro das fístulas, defendido na literatura por Melo et al. (2009), que diz que a remoção das crostas com solução antisséptica a base de iodopovidona, deve ser realizada diariamente durante quinze dias consecutivos ou até total cicatrização. Quanto à termoterapia instituída, aplicação do calor aumenta a taxa metabólica local e induz o aumento da pressão hidrostática intravascular, produzindo vasodilatação das arteríolas e o aumento de fluxo sanguíneo nos capilares. Condições que favorecem o aumento no fornecimento de oxigênio, de anticorpos, leucócitos, enzimático de outros nutrientes, quando necessários na resolução da inflamação. Tal evento aumenta a velocidade da reação química e a cicatrização de tecidos distendidos ou lacerados (Thomassian, 2005; Thomassian, 2006).

O dimetilsufóxido $\left(\right.$ Dimesol $\left.^{\circledR}\right)$ tem características anti-inflamatórias, a droga inibe a migração celular leucocitária, a produção de anticorpos e a proliferação de fibroblastos. Sua capacidade analgésica foi testada in vitro alcançando bloqueio nervoso; porém, in vivo é improvável que ocorra concentrações suficientes para tal resposta. As aplicações relatadas ao uso de DMSO incluem cicatrização de feridas, incluindo habronemose em equinos, inflamação, edema entre outras, como defendido por Smith (1993) e que justifica o uso desta medicação no tratamento da linfangite ulcerativa.

Nos curativos foram utilizados dois tipos de pomadas, uma produzida com unguento, penicilina benzatina e rifamicina e outra pomada a base de gentamicina. Sureshjani et al. (2015) sugerem que se o agente causador for $R$. equi será sensível a gentamicina, azitromicina e a eritromicina, e quanto a sensibilidade dos agentes infecciosos aos antibióticos utilizados, o protocolo utilizado entra de acordo com o estudo realizado por Nogradi et al. (2012).

\section{Conclusão}

A linfangite ulcerativa se mostra uma patologia, em sua maioria, secundária a lesões ou traumas, e que causa danos na saúde animal podendo ou não deixar sequelas no mesmo, afetando principalmente o sistema locomotor, e influenciando no desempenho do animal em qualquer que seja a atividade desempenhada por ele. 


\section{Referências bibliográficas}

Giguère, S., Prescott, J. F., Baggot, J. D., Walker, R. D. \& Dowling, P. M. (2010). Terapia antimicrobiana em medicina veterinária. São Paulo, São Paulo, Brasil: Roca.

Guedes, M. T., Souza, B. C., Sousa, T. J., Loureiro, D., Moura-Costa, L. F., Azevedo, V., . . Portela, R. W. (2015). Infecção por Corynebacterium pseudotuberculosis em equinos: aspectos microbiológicos, clínicos e preventivos. Pesquisa Veterinária Brasileira, 35(8):701-708.

Matheus, J. P. C., Milani, J. G. P. O., Gomide, L. B., Volpon, J. B. \& Shimano, A. C. (2008). Análise biomecânica dos efeitos da crioterapia no tratamento da lesão muscular aguda. Revista Brasileira Medicina no Esporte, 14(4):372-375.

Melo, U. P., Ferreira, C., Fiório, R. C., Araújo, T. B. S. \& Santos, P. M. P. (2009). Linfangite aguda e síndrome da resposta inflamatória sistêmica secundárias à dermatofilose generalizada em um equino. Acta Veterinaria Brasilica, 3(1):33-37.

Meselu, D., Abebe, R. \& Mekibib, B. (2018). Prevalence of Epizootic Lymphangitis and Bodily Distribution of Lesions in Cart-Mules in Bahir Dar Town, Northwest Ethiopia. Journal of Veterinary Science \& Technology, 9 (1): 509. doi:10.4172/2157-7579.1000509

Moreira, N. B., Artifon, E. L., Meireles, A., Silva, L. I., Rosa, C. T. \& Bertolini, G. R. F. (2011). A influência da crioterapia na dor e edema induzidos por sinovite experimental. Fisioterapia $e$ Pesquisa, 18(1):79-83.

Mueller, R. S. (2007). Dermatologia para veterinários de equinos. São Paulo, São Paulo, Brasil: Rocca.

Nogradi, N., Spier, S. J., Toth, B. \& Vaughan, B. (2012). Musculoskeletal Corynebacterium pseudotuberculosis infection in horses: 35 cases (1999-2009). Journal of the American Veterinary Medical Association, 241(6):771-777.

Pereira, A. L. C., Bolzani, F. C. B., Stefani, M. \& Charlín, R. (2007). Uso sistémico de corticosteróides: revisión de literatura. Medicina Cutánea Ibero-Latino-Americana, 35(1):35-50.

Quinn, P. J., Markey, B. K., Carter, M. E., Donnelly, W. J. \& Leonard, F. C. (2005). Microbiologia veterinária e doenças infecciosas. Porto Alegre: Artmed.

Radostits, O. M., Gay, C. C., Blood, D. C., Hinchcliff, K. W. \& McKenzie, R. A. (2010). Clínica Veterinária: um tratado de doenças dos bovinos, ovinos, suínos, caprinos e eqüinos (Vol. 1). Rio de Janeiro: Guanabara Koogan.

Reed, S. M., Bayly, W. M. \& Sellon, D. C. (2009). Equine internal medicine: Elsevier Health Sciences.

Smith, B. P. (1993). Tratado de medicina interna de grande animais. São Paulo, São Paulo, Brasil: Manole.

Smith, M. O. (2006). Tratado de medicina interna de grandes animais (Vol. 1). São Paulo: Manole.

Spinosa, H. S., Górniak, S. L. \& Bernardi, M. M. (2002). Farmacologia aplicada à medicina veterinária. Rio de Janeiro: Guanabara Koogan.

Sureshjani, M. H., Atyabi, N., Tazikeh, A., Falahatipour, S. K. \& Hashemian, M. (2015). Isolation of Rhodococcus equi from a mule with cutaneous wound. Comparative Clinical Pathology, 24(3):691693.

Thomassian, A. (2005). Enfermidades dos cavalos. Sao Paulo, Brasil: Livraria Varela.

Thomassian, A. (2006). Enfermidades dos cavalos. São Paulo, Brasil: Livraria Varela.

Recebido: 26 de julho, 2019.

Aprovado: 21 de setembro, 2019.

Publicado: 11 de dezembro, 2019

Licenciamento: Este artigo é publicado na modalidade acesso aberto sob a licença Creative Commons Atribuição 4.0 (CC-BY 4.0), a qual permite uso irrestrito, distribuição, reprodução em qualquer meio, desde que o autor e a fonte sejam devidamente creditados. 